\title{
Proline racemases: insights into Trypanosoma cruzi peptides containing D-proline
}

\author{
Nicolas Coatnoan, Armand Berneman, Nathalie Chamond, Paola Minoprio/ ${ }^{+}$ \\ Institut Pasteur, Laboratoire d'Immunobiologie des Infections à Trypanosoma, Département d'Immunologie, 25 Rue du Dr. Roux, 75724 \\ Paris, Cedex 15, France
}

Trypanosoma cruzi proline racemases (TcPRAC) are homodimeric enzymes that interconvert the $L$ and $D$ enantiomers of proline. At least two paralogous copies of proline racemase (PR) genes are present per parasite haploid genome and they are differentially expressed during T. cruzi development. Non-infective epimastigote forms that overexpress $P R$ genes differentiate more readily into metacyclic infective forms that are more invasive to host cells, indicating that PR participates in mechanisms of virulence acquisition. Using a combination of biochemical and enzymatic methods, we show here that, in addition to free D-amino acids, non-infective epimastigote and infective metacyclic parasite extracts possess peptides composed notably of D-proline. The relative contribution of TcPRAC to D-proline availability and its further assembly into peptides was estimated through the use of wild-type parasites and parasites over-expressing TcPRAC genes. Our data suggest that D-proline-bearing peptides, similarly to the mucopeptide layer of bacterial cell walls, may be of benefit to T. cruzi by providing resistance against host proteolytic mechanisms.

Key words: proline racemase - TcPRAC - D-proline

The role of D-amino acids (D-AA) in physiopathological processes has occupied the attention of several groups for many years. Although believed to be "unnatural," D-AA residues are present in both prokaryotes and eukaryotes, in various organelles and tissues (Fisher 2007). Recent studies have shown that free D-AAs play relevant roles in various phisiological processes in higher organisms, including ontogeny, differentiation, neuronal and hormonal secretion, and even aging (Collingridge 1987, Fujii 2005, D’Aniello 2007). Interestingly, specific levels of D-AAs found in the human brain, cerebrospinal fluid and serum have been implicated with physiopathological processes, including schizophrenia, epilepsy, Alzheimer's brain degeneration and renal diseases (Nagata et al. 1987, Fisher et al. 1998, Fuchs et al. 2005).

Amino acid racemases (AAR), enzymes that reversibly catalyse the interconversion of free L-AAs and DAAs, were until recently found only in prokaryotes and were primarily associated with the synthesis of bacterial cell layer components that operate as natural defences against proteolytic mechanisms set in motion by hosts (Walsh 1989, Caceres et al. 1997, Thompson et al. 1998). Accordingly, bacterial cell wall assembly requires complex biosynthetic processes that utilise both L-AAs and

Financial support: Institut Pasteur Fonds dédiés n 17 (Sanofi-Aventis, Ministère de la Recherche)

+ Corresponding author: pmm@pasteur.fr

$\mathrm{NCo}$ and $\mathrm{AB}$ contributed equally to this work.

Received 10 March 2009

Accepted 8 June 2009
D-AAs to provide an envelope composed of peptidoglycans, teichoic acid, polysaccharides and proteins (Marraffini et al. 2006). For instance, D-alanine is required for mucopeptide synthesis and growth in most bacteria and it has been implicated with the acquisition of resistance to host-induced humoral and cellular defences against Listeria monocytogenes and Staphylococcus spp. (MacArthur \& Archibald 1984, Thompson et al. 1998). The genetic modification of AAR and transferase genes has produced attenuated bacterial mutants that are unable to grow in standard in vitro and in vivo conditions and that exhibit high susceptibility to host defensins, protegrines, anti-bacterial peptides and cytotoxic $\mathrm{T}$ cell responses (Caceres et al. 1997, Peschel et al. 1999). More complex peptides bearing D-AAs were isolated from invertebrates and vertebrates, such as frog dermophin, crustacean and cephalopod neurohormones and cyanobacteria hepatotoxins (Montecucchi et al. 1981, Richter et al. 1987, Mignogna et al. 1998).

Proline racemase, a dimeric enzyme, was firstly isolated from the Clostridium sticklandii protobacterium by Cardinale and Abeles, in 1968. A eukaryotic proline racemase was first isolated and characterised from the human pathogenic parasite Trypanosoma cruzi (TcPRAC) (Reina-San-Martin et al. 2000), and more recently the enzyme has been found in other pathogens (Goytia et al. 2007, Chamond et al. 2009). The identification of intracellular and secreted isoforms of TCPRAC brought up the question of its role in parasite biology. Several hypotheses have been raised, such as that the enzyme may participate in the mechanisms leading to parasite differentiation by regulating intracellular proline metabolic pathways through the conversion of free L-proline (L-pro) internalised from the vector digestive tract (Chamond et al. 
2003, 2005). It has also been hypothesised that $T c$ PRAC contributes to the parasite's evasion strategies by making D-proline (D-pro) available for post-translational addition into peptide chains (Reina-San-Martin et al. 2000). This hypothesis is appealing since the incorporation of D-AA residues into peptide sequences would make them less immunogenic than those exclusively composed of L-analogues (Sela \& Zisman 1997). In this regard, it has been reported that the addition of a single D-AA in the $\mathrm{N}$-terminus of a protein is sufficient to confer general resistance to host proteolytic enzymes (Janeway \& Humphrey 1970). Therefore, the incorporation of D-pro into expressed T. cruzi proteins could benefit the parasite by contributing to the initial lack of specificity of host Bcell responses and by improving parasite resistance to host cellular and extracellular proteases.

We used biochemical and enzymatic approaches to verify the presence of D-AAs, and more precisely that of D-pro, in extracts of epimastigote (EPI) and metacyclic (META) forms of T. cruzi. Soluble (SF) and non soluble (NSF) parasite fractions were prepared, subjected to successive digestions with endoproteases and amino and carboxy- peptidases, and further fractionated by preparative thin-layer chromatography. All positive layer sections that were deduced from ninhydrin-sensitive borders of the plate were scrapped off, resuspended in water and tested for the presence of D-AAs. D-amino acid oxidase (D-AAOx-) positive fractions were further separated by thin-layer chromatography using chiral plates to separate free AA stereoisomers and small peptides. When compared to simultaneously run $\mathrm{L}$ and D-AA standards, the ninhydrin-stained plates containing the extracts from the EPI and META forms (Fig. 1A, B) illustrate the resolution of the method and the chiral separation of the extracts. First, with regard to the spots on the NSF chromatograms, the major differences observed between the EPI and META forms were related to the migration path fingerprint. It can be observed that after the drastic physical and proteolytic treatment of the samples, the resulting insoluble material contains proteins that were not degraded (stained in red) as well as non-protein polymers that do not react with ninhydrin generating a white background path. These macromolecules that interfere with the migration of the samples may explain why some components are carried farther up the plates than others. In addition, varying polarities of the molecules composing the EPI and META NSFs may also explain the varying strength of adsorption to the absorbent and the observed migration profiles. The data also show that most of the EPI and META extract proteins were digested and their ensuing contents are thus found in SF fractions. However, although qualitative, the technique highlights increasing amounts of material in the chromatograms from META SFs as compared to those from EPI SFs. Duplicates of the plates were then stained with isatin (1H-indole-2,3-dione), a proline-specific dye, and this clearly revealed the presence of both D-pro and L-pro in the SFs (Fig. 1C, D). Interestingly, spots corresponding to $\mathrm{D}$ and L-pro were more intense in META SFs than in EPI SFs.
In an attempt to quantitate the presence of D-AA bound to peptide chains, all the fractions were assayed for D-AA content throughout all stages of fractionation. Since EPI and META forms differ in size, nucleic acid and protein contents, data were adjusted to the water volume corresponding to $10^{8}$ parasites, as described by Rohloff, in 2003 (Table). To assess the impact of proline uptake on the availability of substrate for the intracellular isoforms of TcPRAC, the experiments used EPIs conventionally grown in LIT medium and METAs that had issued from EPIs differentiating in TAU medium supplemented with $10 \mathrm{mM}(1 \mathrm{X})$ or $30 \mathrm{mM}$ (3X) L-pro. The Table depicts the total D-AA concentration obtained from the EPI and META forms. The total concentration of putative D-AAs bound to polypeptides or to small peptides was deduced from the total amount of D-AAs obtained before and after the enzymatic processing of the samples. The data from samples analysed before any protease treatment revealed that extracts from META parasites possess three times more free D-AAs than EPIs. Moreover, a two-fold greater D-AA concentration was observed in the samples from META extracts $(0.31 \mathrm{mM})$ as compared to EPI extracts $(0.15 \mathrm{mM})$ after biochemical fractionation, indicating the presence of D-AAs bound to peptide chains. Interestingly, while extracts from META parasites generated in 3X L-procontaining medium showed modestly elevated free D-AA content $(4.10 \mathrm{mM})$ relative to $1 \mathrm{X}$-derived METAs (3.96 $\mathrm{mM})$, they yielded five times more bound D-AAs $(0.83 \mathrm{mM})$ than EPIs. Although the DAAOx test cannot discriminate different D-AAs, intracellular increases in D-pro resulting from racemisation of L-pro by TcPRAC may well account for these differences. Nevertheless, the results obtained suggest that the concentration of free D-AAs and in particular that of D-AAs bound to small peptides or to larger polypeptides, increases during metacyclogenesis.

In order to gain further insights into the participation of TcPRAC isoforms in the biosynthesis of D-Pro, experiments were conducted to compare wild-type (WT) parasites to mutants overexpressing different TcPRAC genes (Chamond et al. 2005). Thus, the paralogous genes TcPRACA $\left(\mathrm{A}^{+}\right)$and TcPRACB $\left(\mathrm{B}^{++}\right)$were overexpressed in non-infective EPI forms using appropriate vectors to obtain stable chromosomal integration of these genes in sense and antisense orientations. It is worth noting that non-infective forms of the parasite expressing full length antisense $T c P R A C B$ RNA [functional knockdown (KD)] are not viable, whereas functional TcPRACA-KD (A-) EPIs survive only poorly even under low selection pressure for recombinant parasites. Consistent with our hypothesis, extracts from parasites overexpressing TcPRAC genes display more D-AA-containing peptides than WT or KD controls after physical and biochemical fractionation. Specifically, the META/EPI D-AA ratio obtained from parasites that developed in higher concentrations of proline ( $\sim 5.5)$ was greater than the META/EPI DAA ratio from WT $(\sim 2)$. Furthermore, parasites overexpressing the intracytoplasmic isoform of proline racemase $\left(\mathrm{B}^{++}\right)$that had differentiated in $1 \mathrm{X}$ or $3 \mathrm{X}$ proline con- 


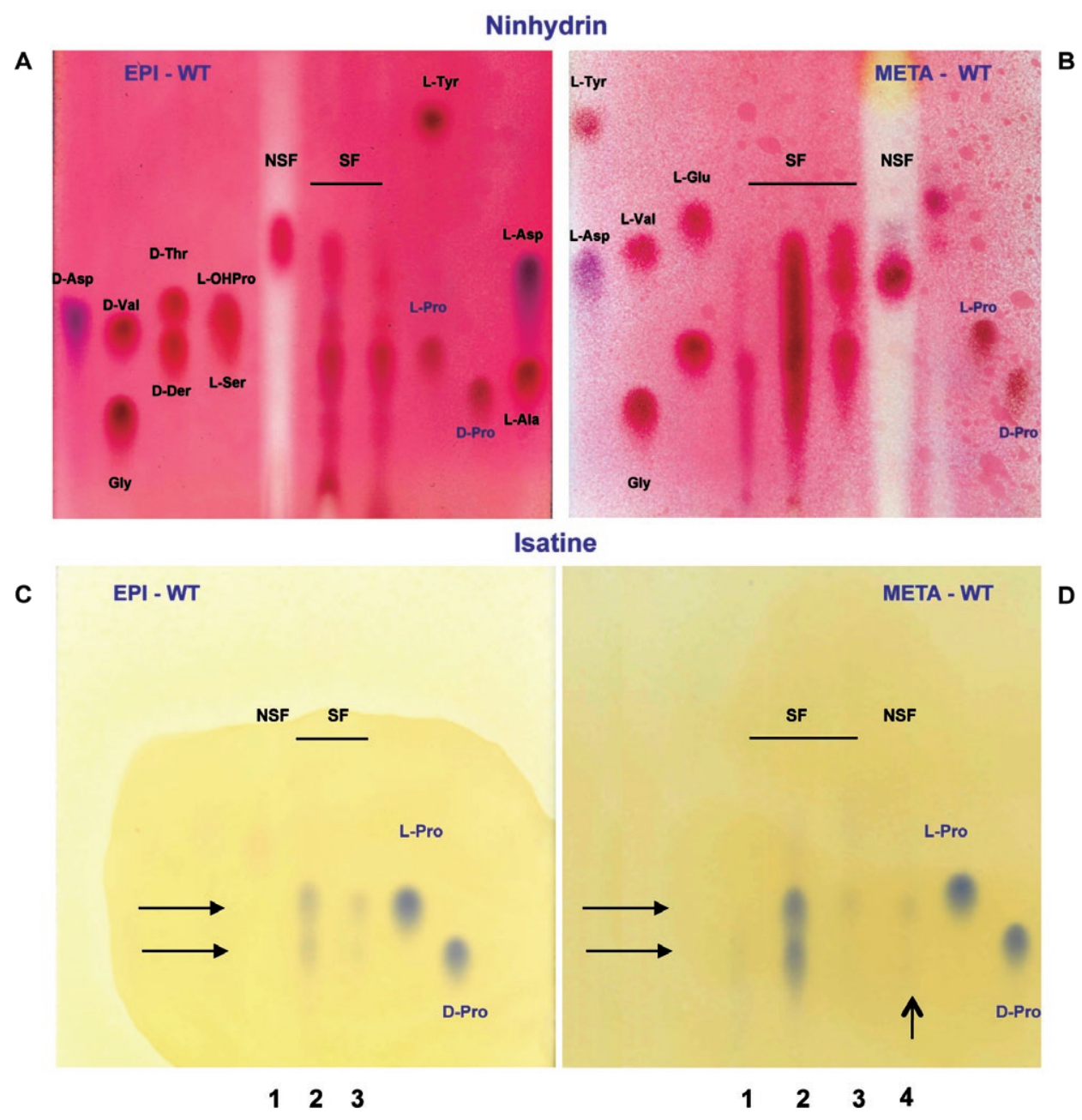

Fig 1: chiral thin layer chromatography of epimastigote (EPI) (A, C) and metacyclic (META) (B, D) extracts of Trypanosoma cruzi (CL Brener, F11F5 clone). EPI forms were maintained at $27^{\circ} \mathrm{C}$ by weekly passage in LIT medium. In vitro metacyclogenesis was accomplished in a proteinfree defined TAU medium and META forms were purified using a DEAE-51 cellulose column, as described before (de Sousa 1983, Contreras et al. 1985). Purity of META preparations was ascertained by microscopy to verify the position of the kinetoplast at the posterior end of the parasite, using slides appropriately stained with Giemsa. Parasites were extensively washed in TBS and extracts were prepared by physical and biochemical fractionations. Physical fractionation consisted of $10 \mathrm{X}$ freezing/thawing $\left(-80 / 37^{\circ} \mathrm{C}\right), 10 \mathrm{mn}$ sonication at $4^{\circ} \mathrm{C}$ and further resuspension in TBS $/ 0,05 \%$ NP40. Preparations were subjected to Potter douncing (minimum of 40 strokes) and centrifugated at $3800 \mathrm{~g}$ for $20 \mathrm{~min}$ at $4^{\circ} \mathrm{C}$. Pellets were referred as non soluble fractions (NSF) and supernatants as soluble fractions (SF). Fractions were subjected to biochemical fractionation to obtain free amino acids and small peptides. Successive proteolytic treatments consisted of : pronase I (Roche Diagnostics), 7 units $/ \mathrm{mL}, \mathrm{pH} 7.5$ at $40^{\circ} \mathrm{C}$ for $24 \mathrm{~h}$, for endopeptidase activity; pronase II, 7 units $/ \mathrm{mL}, \mathrm{pH} 8.2$ at $25^{\circ} \mathrm{C}$ for $24 \mathrm{~h}$, for chimotrypsine-like activity; pronase III, 7 units $/ \mathrm{mL}, \mathrm{pH} 7.5$ at $25^{\circ} \mathrm{C}$ for $24 \mathrm{~h}$, aminopeptidase I activity. Fractions were finally treated with carboxypeptidase W (Sigma), 2 units $/ \mathrm{mL}, \mathrm{pH} 4.0,30^{\circ} \mathrm{C}$ for $24 \mathrm{~h}$. At various stages of fractionation, protein concentration was determined by both the Lowry method and the Bradford method using "Biorad protein assay" reagent (Biorad laboratories) and BSA as standard. D-amino acids (D-AA) concentration in the different fractions was equally determined before and after the different treatments by the D-amino acid oxidase (D-AAOx) assay (Table). Fractions were analyzed immediately by thin layer chromatography (TLC) or conserved at $-20^{\circ} \mathrm{C}$ until use. Preparative separation of all D-AA positive fractions was performed on silica gel TLC (Macherey \& Nagel). D-AA positive lysates were loaded as a line at the basis of a $1 \mathrm{~mm}$ thick SilG-100 precoated plate. Chromatography was run with methanol/chloroform/ammonia 17\% (2:2:1 vol/vol). After 3-4 h migration, one border of the plate was stained with ninhydrin $(0.3 \%$ in acetone) to partially reveal the limits of the chromatogram of the mixture of free amino acids and small peptides present in the hydrolyzed samples. The plates, possessing a fluorescent indicator, allowed the full visualization under U.V. ${ }_{.254}$ light of the whole chromatogram in non stained regions. All chromatogram visualized zones were then scrapped off and eluted individually in $0.1 \mathrm{M}$ ammonium acetate, lyophilized and resuspended in the minimum volume of water $(100-200 \mu \mathrm{L})$ in order to concentrate the samples. Chromatogram zones assessed positive by the D-AAOx test were then submitted to a new chromatography using chiral plate reversed phase TLC plates (Macherey \& Nagel) for the separation of optically active stereoisomers. Each sample corresponding to $200 \mu \mathrm{g}$ of parasite protein before biochemical fractionation was spotted on two $0.25 \mathrm{~mm}$ thick silica chiral plates along with samples of different purified L-AA and D-AA enantiomers, as controls. Chromatographies were performed for the different samples on duplicate plates with methanol, water, acetonitrile, $(1: 1: 4 \mathrm{v} / \mathrm{v})$. One of the plate duplicates was stained with ninhydrin $(0.3 \%$ in acetone) in order to reveal L-AA and D-AA (A and B, respectively for EPI and META forms). The other plate duplicate was stained with isatin ( $0.2 \%$ in butanol with $10 \%$ acetic acid) to specifically reveal proline enantiomers present in the samples (C and D, respectively for EPI and META forms) (Elliot \& Gardner 1976). Non soluble fractions are depicted in Lanes $1(\mathrm{~A}, \mathrm{C})$ or $4(\mathrm{~B}, \mathrm{D})$; different chromatogram zones containing soluble fractions that were positive in the D-AAOx test are shown in Lanes 2 and $3(\mathrm{~A}, \mathrm{C})$ or 1, 2 and $3(\mathrm{~B}, \mathrm{D})$. 
TABLE

Relative quantification of D-amino acids (D-AA) containing peptides in Trypanosoma cruzi soluble extracts

\begin{tabular}{|c|c|c|c|}
\hline \multirow[b]{2}{*}{ T. cruzi forms } & \multicolumn{3}{|c|}{ Total D-AA $(\mathrm{mM})^{b}$} \\
\hline & $\begin{array}{c}\text { Free }^{a} \\
\text { (before digestion) }\end{array}$ & $\begin{array}{c}\text { Total free }^{a} \\
\text { (after digestion) }\end{array}$ & $\begin{array}{l}\text { Originally } \\
\text { bound }^{d}\end{array}$ \\
\hline Epimastigotes & 1.26 & 1.41 & 0.15 \\
\hline Metacyclics $1 \mathrm{X}^{c}$ & 3.96 & 4.27 & 0.31 \\
\hline Metacyclics 3X & 4.10 & 4.93 & 0.83 \\
\hline
\end{tabular}

$a$ : the concentration of D-AA was determined before (free) and after (total free) all stages of biochemical fractionation of parasite extracts by a D-amino acid oxidase/HPR microtiter plate test (A Berneman et al., unpublished observations), where the specific oxidation of D-AA by D-amino acid oxidase (D-AAOx-) in the presence of flavin-adenine dinucleotide co-factor (FAD) generates stoechiometric amounts of hydrogen peroxyde $\left(\mathrm{H}_{2} \mathrm{O}_{2}\right)$, readily quantitated colorimetrically by peroxidase/orthophenylene diamine (OPD) reactions. Briefly, $50 \mu \mathrm{L}$ of experimental samples or serial dilution of L-AA and D-AA standards were diluted in $0.2 \mathrm{M}$ sodium acetate/0.016 M sodium pyrophosphate buffer, $\mathrm{pH} 8$ (solution $\mathrm{A}$ ) and loaded per well. $50 \mu \mathrm{L}$ of solution A containing $1 \mathrm{U} / \mathrm{mL}$ for D-AAOx, $0.5 \mathrm{mg} / \mathrm{mL}$ OPD (Sigma), $38 \mathrm{U} / \mathrm{mL}$ HRP and FAD $\left(1.5 \times 10^{-5} \mathrm{M}\right)$ were added to the wells. Plates were incubated for $1 \mathrm{~h}$ at $37^{\circ} \mathrm{C}$ in the dark and the reactions were stopped with $50 \mu \mathrm{L}$ of $3 \mathrm{NHCl}$. OD at $490-650 \mathrm{~nm}$ were obtained with a microtiter plate reader (molecular devices) and compared to those obtained with blank control wells; $b$ : since epimastigote and metacyclic forms vary in size, nucleic acids and protein contents, values corresponding to the $1 \times 10^{8}$ parasites used for the extract preparations were adjusted to the $\mathrm{H}_{2} 0$ volume as described by Rohloff et al. (2003), where epimastigote and metacyclic respective volumes were considered to be approximatively $3.48 \mathrm{~mL} / 10^{8}$ cells and $1.11 \mathrm{~mL} / 10^{8}$ cells; $c$ : DEAE-51 purified metacyclic parasites (de Sousa 1983) obtained by in vitro metacyclogenesis of epimastigote forms of T. cruzi in TAU medium containing $1 \mathrm{X}(10 \mathrm{mM})$ or $3 \mathrm{X}(30 \mathrm{mM})$ L-proline; $d$ : originally bound values correspond to the substraction of free amounts of D-AA (before digestion) from total free D-AA (after digestion) obtained values.

ditions displayed higher META/EPI D-AA ratios than the respective WT controls. Interestingly, although they present a relative increase in META/EPI D-AA ratios, overexpressors of the secreted version of TcPRAC $\left(\mathrm{A}^{+}\right)$ show lower levels of D-AAs than $\mathrm{WT}$ or $\mathrm{B}^{++}$parasites. Since TcPRACA transcripts appear to be more highly expressed at the end of metacyclogenesis (Fig. 3), it is tempting to consider that racemisation of intracellular proline during this stage of development instead depends on the cytoplasmic version of the enzyme (TcPRACB). Fig. 2B shows preliminary data from chiral thin layer chromatography (TLC) plates of extracts of two and three SF fractions obtained from METAs overexpressing $T c P R A C A\left(\mathrm{~A}^{+}\right)$and $T c P R A C B\left(\mathrm{~B}^{++}\right)$, respectively, compared to WT parasites. Given that the plates were
A

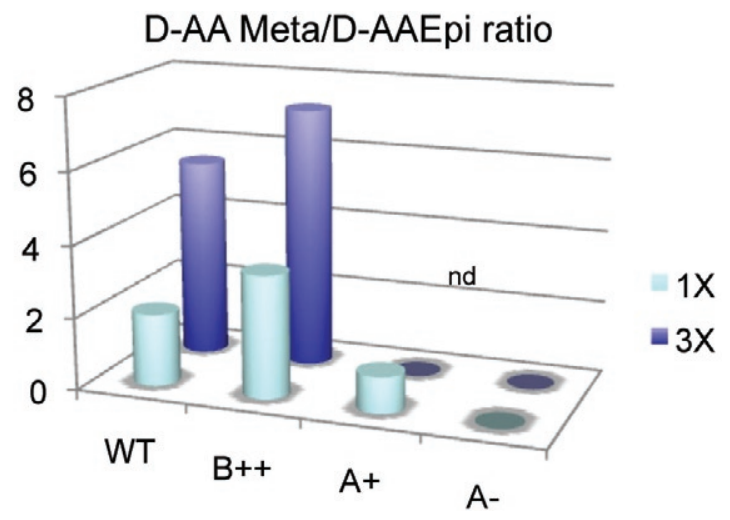

B

Meta 1X
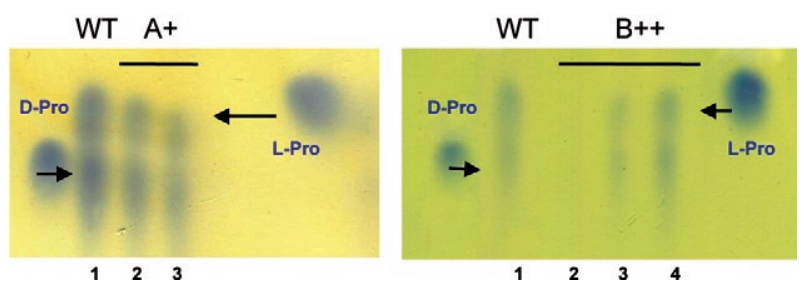

Fig. 2: expression of total D-amino acids (D-AA) contents and Dproline by wild-type (WT) CL-Brener parasites (clone F11F5) and by overexpressors of Trypanosoma cruzi proline racemases (TcPRAC) genes $\left(\mathrm{B}^{++}, \mathrm{A}^{+}\right.$and $\mathrm{A}^{-}$) (Chamond et al. 2005). WT, $\mathrm{B}^{++}, \mathrm{A}^{+}$and $\mathrm{A}^{-}$ epimastigotes (EPI) were induced to metacyclogenesis in TAU medium containing $1 \mathrm{X}(10 \mathrm{mM})$ or $3 \mathrm{X}(30 \mathrm{mM})$ L-proline. Free D-AA contents were determined by the D-amino acid oxidase (D-AAOx) in extracts obtained from DEAE-51 purified metacyclic parasites (META) and compared to extracts of respective EPI forms before and after physical and biochemical fractionations. To allow comparisons between EPI an META parasites, calculations were done using values adjusted to the respective $\mathrm{H}_{2} 0$ volume of $1 \times 10^{8}$ parasite forms, as detailed in the legend to the Table. A: depicts META/EPI peptide-bound D-AA ratios [(free + bound) - free D-AA] obtained for the different parasite extracts. Metacyclogenesis performed with $1 \mathrm{X}$ (light bars) or $3 \mathrm{X}$ (dark bars) proline concentrations; B: chiral thin layer chromatographies of different soluble zones of the chromatograms (Lanes 2-4) obtained after physical and biochemical treatments of extracts from purified META forms of TcPRACA $\left(\mathrm{A}^{+}\right)$or $T c$ PRACB $\left(\mathrm{B}^{++}\right)$overexpressors or from META WT parasites (Lane 1). Since $\mathrm{A}^{+}$and $\mathrm{B}^{++}$ transgenic parasites present different rates of growth in culture, our preliminary experiments presented in the figure do not allow straight comparisons between the mutants. However, even if the approach is only qualitative, comparable protein contents of WT and mutant parasite fractions were spotted in the chiral plates in each independent experiment. Plates were stained with isatin, a specific stain for proline. L and D-proline enantiomers were spotted as controls; nd: not determined; Arrows indicate the coexistence of both D-proline and L-proline in the extracts.

developed with isatin, which specifically stains proline, these experiments demonstrate that in addition to free D-AAs, META extracts submitted to successive proteolytic treatments specifically contain elevated amounts of D- proline bound to small peptides or polypeptide chains. Corroborating the above hypothesis, although the methodology used is not quantitative, SF fractions of $\mathrm{B}^{++}$META mutants extracted from two zones of the TLC 
In vitro METACYCLOGENESIS WT-EPI TauA TauB Day 1 Day 2 Day 3 Day 4

A

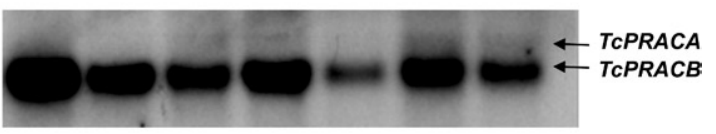

B

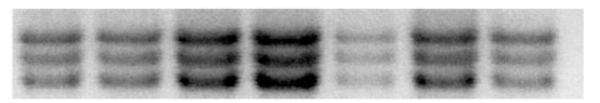

Fig. 3: panel A: Trypanosoma cruzi proline racemases (TcPRACA and $T c P R A C B)$ expression before and during metacyclogenesis. Total RNA was prepared by conventional methods from washed wild-type (WT)-epimastigotes (EPI) or starved (TauA) EPI and from parasites in the beginning of the differentiation process (TauB) and everyday thoroughly until day 4 of metacyclogenesis as indicated. $10 \mu \mathrm{g}$ of total RNA was tranferred to a Hybond $\mathrm{N}^{+}$membrane and hybridized with single stranded DNA labeled with $\mu^{32} \mathrm{PdCTP}$, complementary to and covering the entire TCPRACA gene transcript; panel B: methylene blue staining of ribosomal RNAs is displayed below each lane.

chromatogram exhibit considerable amounts of D-pro as compared to the amount observed in equivalent protein amounts of WT META SF extracts (Fig. 2).

The presence of D-AA in (poly) peptide chains has been credited to various strategies, including replacement or addition of stereoisomers in peptides recently synthesised by ribosomes, post-translational conversion of non-chiral D-residues by amino acid synthetases, and polymerisation of monomers in an assembly-linelike biosynthesis by non-ribosomal peptide synthetases (Xie \& van der Donk 2004, Jilek et al. 2005). The pharmacokinetic advantages of synthetic peptides and their extended half-life and improved stability and resistance to proteases (Janeway \& Humphrey 1970, Thompson et al. 1998) have generated considerable interest. Moreover, data are accumulating on the differential immunogenic properties of $\mathrm{D}$-enantiomers and the poor ability of D-polymers to activate B lymphocyte responses (Sela \& Zisman 1997). Some examples include the induction of immunological paralysis following the injection of multichain polypeptides built exclusively of Dresidues and the discrimination and stereospecificity of antibodies raised against peptides whose sequences are composed of L or D-AAs. The origin of free D-AAs is less clear than that of protein bound D-AAs. However, the recent discovery of a functional proline racemase in $T$. cruzi and other important pathogens (Goytia et al. 2007, Chamond et al. 2009) has uncovered endogenous and intracellular means of D-pro production, raising the question of its specific functions. Moreover, the identification in parasite extracts of D-AAs, and more specifically of D-pro, may reflect cell adaptive responses and point to more general mechanisms for the regulation of protein and peptide expression by D-AA racemases. Since T. cruzi needs TcPRAC activity for metacyclogenesis, as suggested by our previous data (Chamond et al. 2005), the enzyme could be in- volved in parasite metabolic processes leading to the post-translational modification of recently synthesised proteins or peptides. It is also possible that the parasite uses racemisation to synthesise and/or express new peptides bearing D-pro to avoid or reduce host-induced proteolysis. The identities of the parasite proteins bearing D-pro should be investigated, as these may reveal attractive targets involved in parasite evasion.

\section{ACKNOWLEDGEMENTS}

To A. Cosson, for handling some cultures.

\section{REFERENCES}

Caceres NE, Harris NB, Wellehan JF, Feng Z, Kapur V, Barletta RG 1997. Overexpression of the $\mathrm{D}$-alanine racemase gene confers resistance to D-cycloserine in Mycobacterium smegmatis. $J$ Bacteriol 179: 5046-5055.

Cardinale GJ, Abeles RH 1968. Purification and mechanism of action of proline racemase. Biochemistry 7: 3970-3978.

Chamond N, Cosson A, Coatnoan N, Minoprio P 2009. Proline racemases are conserved mitogens: characterization of a Trypanosoma vivax proline racemase. Mol Biochem Parasitol 165: 170-179.

Chamond N, Goytia M, Coatnoan N, Barale JC, Cosson A, Degrave WM, Minoprio P 2005. Trypanosoma cruzi proline racemases are involved in parasite differentiation and infectivity. Mol Microbiol 58: 46-60.

Chamond N, Gregoire C, Coatnoan N, Rougeot C, Freitas-Junior LH, da Silveira JF, Degrave WM, Minoprio P 2003. Biochemical characterization of proline racemases from the human protozoan parasite Trypanosoma cruzi and definition of putative protein signatures. J Biol Chem 278: 15484-15494.

Collingridge G 1987. Synaptic plasticity. The role of NMDA receptors in learning and memory. Nature 330: 604-605.

Contreras VT, Salles JM, Thomas N, Morel CM, Goldenberg S 1985. In vitro differentiation of Trypanosoma cruzi under chemically defined conditions. Mol Biochem Parasitol 16: 315-327.

D'Aniello A 2007. D-aspartic acid: an endogenous amino acid with an important neuroendocrine role. Brain Res Rev 53: 215-234.

Elliot RJ, Gardner DL 1976. Proline determination with isatin, in the presence of amino acids. Anal Biochem 70: 268-273.

Fisher G, Lorenzo N, Abe H, Fujita E, Frey WH, Emory C, Di Fiore MM, A DA 1998. Free D- and L-amino acids in ventricular cerebrospinal fluid from Alzheimer and normal subjects. Amino Acids 15: 263-269.

Fisher GH 2007. Biologically active D-amino acids. Amino Acids 32: 1.

Fuchs SA, Berger R, Klomp LW, de Koning TJ 2005. D-amino acids in the central nervous system in health and disease. Mol Genet Metab 85: 168-180.

Fujii N 2005. D-amino acid in elderly tissues. Biol Pharm Bull 28: 1585-1589.

Goytia M, Chamond N, Cosson A, Coatnoan N, Hermant D, Berneman A, Minoprio P 2007. Molecular and structural discrimination of proline racemase and hydroxyproline-2-epimerase from nosocomial and bacterial pathogens. PLOS ONE 2: e885.

Janeway CA, Humphrey JH 1970. Synthetic antigens composed exclusively of L or D- amino acids. II. Effect of optical configuration on the metabolism and fate of synthetic polypeptide antigens in mice. Folia Biol 16: 156-172. 
Jilek A, Mollay C, Tippelt C, Grassi J, Mignogna G, Mullegger J, Sander V, Fehrer C, Barra D, Kreil G 2005. Biosynthesis of a $\mathrm{D}$-amino acid in peptide linkage by an enzyme from frog skin secretions. Proc Natl Acad Sci USA 102: 4235-4239.

MacArthur AE, Archibald AR 1984. Effect of culture $\mathrm{pH}$ on the D-alanine ester content of lipoteichoic acid in Staphylococcus aureus. J Bacteriol 160: 792-793.

Marraffini LA, Dedent AC, Schneewind O 2006. Sortases and the art of anchoring proteins to the envelopes of gram-positive bacteria. Microbiol Mol Biol Rev 70: 192-221.

Mignogna G, Simmaco M, Barra D 1998. Occurrence and function of D-amino acid-containing peptides and proteins: antimicrobial peptides. Exs 85: 29-36.

Montecucchi PC, de Castiglione R, Piani S, Gozzini L, Erspamer V 1981. Amino acid composition and sequence of dermorphin, a novel opiate-like peptide from the skin of Phyllomedusa sauvagei. Int J Pept Protein Res 17: 275-283.

Nagata Y, Akino T, Ohno K, Kataoka Y, Ueda T, Sakurai T, Shiroshita $\mathrm{K}$, Yasuda T 1987. Free D-amino acids in human plasma in relation to senescence and renal diseases. Clin Sci (Lond) 73: 105-108.

Peschel A, Otto M, Jack RW, Kalbacher H, Jung G, Gotz F 1999. Inactivation of the dlt operon in Staphylococcus aureus confers sen- sitivity to defensins, protegrins and other antimicrobial peptides. J Biol Chem 274: 8405-8410.

Reina-San-Martin B, Degrave W, Rougeot C, Cosson A, Chamond N, Cordeiro-Da-Silva A, Arala-Chaves M, Coutinho A, Minoprio P 2000. A B-cell mitogen from a pathogenic trypanosome is a eukaryotic proline racemase. Nat Med 6: 890-897.

Richter K, Egger R, Kreil G 1987. D-alanine in the frog skin peptide dermorphin is derived from L-alanine in the precursor. Science 238: 200-202.

Sela M, Zisman E 1997. Different roles of D-amino acids in immune phenomena. FASEB J 11: 449-456.

Sousa MA 1983. A simple method to purify biologically and antigenically preserved bloodstream trypomastigotes of Trypanosoma cruzi using DEAE-cellulose columns. Mem Inst Oswaldo Cruz 78: 317-333.

Thompson RJ, Bouwer HG, Portnoy DA, Frankel FR 1998. Pathogenicity and immunogenicity of a Listeria monocytogenes strain that requires D-alanine for growth. Infection and immunity 66 : 3552-3561.

Walsh CT 1989. Enzymes in the D-alanine branch of bacterial cell wall peptidoglycan assembly. J Biol Chem 264: 2393-2396.

Xie L, van der Donk WA 2004. Post-translational modifications during lantibiotic biosynthesis. Curr Opin Chem Biol 8: 498-507. 